\title{
JUSTICIA Y DERECHO
}

Cuando comienza a desenvolverse la reflexión filosófica sobre aquel obscuro sentimiento y sobre aquella vaga idea de justicia que todo hombre encuentra afincada en el propio espíritu, con la finalidad de definir precisamente la esencia de justicia, la atención se fija sobre algunos caracteres generales que parecen denotar precisamente esta esencia, a saber: la igualdad, la armonía, la proporción y el orden.

Estos caracteres se revelan, sin embargo, a un análisis más profundo y exacto, como insuficientes para definir la noción de justicia en lo que a ésta tiene de propio y específico.

Sabido es que ya para los pitagóricos o itálicos, los cuales pueden ser considerados como los iniciadores de la Filosofía del Derecho, la justicia consiste esencialmente en una igualdad. Esta concepción, que tuvo para ellos el valor casi de un descubrimiento, construyó en efecto una adquisición que no fue ya nunca perdida, y al mismo tiempo, un punto de arranque para las ulteriores investigaciones.

La igualdad es en efecto una relación que se aplica a todas las especies cognoscibles de realidad; es un instrumento lógico del pensamiento, una categoría.

PLATÓN, con una visión más compleja, concibió la justicia como armonía entre las diversas partes que integran un todo; y de este concepto, extrajo importantísimas aplicaciones para el estudio del alma humana, así como para el de la sociedad y el del Estado. Pero también este concepto es manifiestamente tan lato que no vale para definir con exactitud la justicia en cuanto a regla de vida en el sentido ético, y mucho menos como una de las posibles especies de reglas de vida. Lo cual no impide, sin embargo, que también el concepto de armonía, así, como el de igualdad, sean elementos preciosos para la verdadera definición de la justicia.

ARISTÓTELES, polemizando a su vez en forma bastante acerba con los pitagóricos, parte, precisamente, de la definición por ellos propuesta, para intentar su perfeccionamiento; y distingue varias especies de igualdad, según los tipos de proporción aritmética y de la proporción geométrica. A la verdad, que en la gran obra aristotélica, las consideraciones sobre justicia son tantas y de tal manera entrelazadas a través de numerosas distinciones (las cuales debían hacer perfectamente el juego

$1 \quad$ Comunicación leida al VIII Congreso Nacional de Filosofía (Roma. 26 de octubre de 1933). -

Algunas de las ideas aquí apuntadas tuvieron ya mayor desenvolvimiento en el ensayo sobre La Justicia. trad. española de L. Rodríguez, Camuñas y C. Sancho, Madrid, dit. Góngora. año 1925. 
a aquellas todavía más numerosas de los escolásticos), que ninguna doctrina sobre el mismo tema puede, incluso, en nuestros días, prescindir de aquellos aspectos del problema que fueron meditados por Estagirita. Lo cual, es tanto más notable cunado la exacta reconstrucción del pensamiento aristotélico ofrece todavía, sobre este asunto, dificultades gravísimas, contra las cuales consumieron en vano sus esfuerzos muchos intérpretes incluso de los más famosos. Puede también observarse que las verdades más luminosas sobre este objeto fueron expuestas por ARISTÓTELES casi de una manera incidental, quizá, sin que él mismo hubiese apreciado plenamente u fundamental importancia. La parte más elaborada de si su doctrina, concerniente a las varias especies de proporciones o igualdades (de donde la distinción de la justicia en distributiva, correctiva o conmutativa, etc.), es, en verdad, la parte menos esencial, y la menos apta para conseguir la deseada definición.

Otro elemento conceptual que aparece ya a través de estas tentativas y que fue objeto de especial meditación por parte de autores antiguos y modernos, es la noción de orden. Se sobrentiende que esta noción está ya implícita en las de igualdad, armonía y proporción; pero, de manera explícita, se ha sostenido también que la justicia no es otra cosa que orden, y que todo elemento resulta accesorio respecto a éste. Sin embargo, aquí debemos, por lo demás observar que la tesis es no precisamente falsa, sino inadecuada; porque el concepto de orden se aplica a toda especie de relaciones, incluso en el mundo físico, además de que en el biológico y en el ético, asumiendo por ello significados diversos, los cuales precisamente es necesario distinguir cuando se quiere llegar a una verdadera definición de la justicia en sentido propio o específico.

Tampoco en esta materia, el lenguaje, por sus frecuentes ambigüedades, puede servirnos de guía segura. Justo puede ser en el lenguaje ordinario, un cálculo aritmético, así como un instrumento que tenga una función precisa o como un plan estratégico o un programa para un fin cualquiera; justa puede ser una previsión o una deliberación, no menos que un reparto, y así sucesivamente. Cualquier clase de correspondencia entre un medio y un fin, cualquier proporción o medida exactamente observada, es estimada justa; a propósito de lo cual, puede señalarse como un mérito de nuestro idioma, que los hace menos imperfecto con relación a otros, la distinción entre justeza y justicia (sustantivos a los que corresponde, sin embargo el mismo adjetivo; justo). Queda con todo esto, fuera de duda que la idea de justicia tiene su más preciso sentido, cuando se la considera como una cierta regla de las acciones humanas; y es éste, el sentido que interesa definir.

Para conseguir, o al menos aproximarse mucho a esta definición, hace falta añadir a aquellas primeras notas genéricas (no falsas, repetimos, pero insuficientes) la nota de intersubjetividad. La justicia es, ciertamente, igualdad, armonía, orden, proporción; pero ellos no solamente en el sentido genérico en el cual se nos presenta como sinónimo de perfección en general o de virtud comprensiva de todas las demás virtudes, sino, más bien en el sentido específico de regla determinada de convivencia den las relaciones entre sujeto y sujeto.

Una escultórea formulación de este concepto fundamental la tenemos en la célebre definición del hecho dada por DANTE: "Jus est realis et personalis hominis ad hominem proportio. que sérvala societatem serval, el corrupta corrumpit" (Mon.

L. II, C. V, 3), la cual constituye verdaderamente un punto luminoso, y para Italia glorioso, en la historia de la filosofía del Derecho; aunque, como ahora veremos, sea fácil descubrir su derivación de precedentes doctrinas; cosa que sin embargo parece haber escapado a algunos (por ejemplo al doctísimo WITTE. en su preciada edición 
de la Monarchia, Vindobonae, 1874, pág. 51, el cual declara con honesta franqueza: "Haec juris definitio, unde sumía sil, necio").

Ya en virtud de un natural proceso dialéctico, se debía pasar casi necesariamente de aquella primera determinación genérica a esta otra más precisa. La igualdad o ecuación indica ciertamente una comparación y una correspondencia entre términos contrapuestos; y esto se infiere hasta de la inicial doctrina pitagórica. Aristóteles dice explícitamente en un ulterior pasaje que la justicia (Stxatocruvq) no es sola y simplemente una virtud que se refiere a otro (7rpog éxepov; Eth, Nik. V, 33 1129 b.25 y siguientes). Semejante referencia, es todavía mejor explicada por SANTO TOMÁS DE AQUINO: "Justitia... importat aequalitatem quamdam ...; aquilitas autem adalterum est... rectum vero quoud est in opere justitiae, etiam praeter compatationem ad agentem, cosntitur per conparationem ad aliitm " (Summa Theologiae 2a 2a Quaest 57, Art.1). Quaest 58, Art. 2). "Per exteriores acciones et per exteriores res, quibus sib invicem homines communicare possunt, attenditur ordinatio itnius hominis ad alterum... Et ideum cum justitia ordinetur ad alterum non est circa totam materiam virtutis mora lis, sed solum circa exteriores acciones et res secundum quamdam retionem objecti specialem, prout scilicet secumdum eas unus homo alteri coordinatur"

(Ib. Quaest 58, Art. 8).

Así de la primera observación según la cual toda igualdad o proporción supone una comparación entre varios términos, se ha pasado a la noción, mucho más importante, de que los términos entre los cuales la justicia establece una tal relación deben ser hombres, o sea sujetos o personas. A esta misma conclusión, por lo demás, habían llegado por otras rutas mejores técnicos de derecho, quiere decirse, los juristas romanos: los cuales habían precisamente enseñado que la relación jurídica es esencialmente un vínculo entre personas.

Filosóficamente, el pleno y profundo significado de esta tesis podría comprenderse sólo con el advenimiento de la crítica gnoseológica, que ha mostrado la necesidad de investigar en la misma naturaleza del espíritu, como sujeto, la raíz de las actitudes o momentos fundamentales de la conciencia; una de las cuales consiste precisamente en que todo sujeto debe pensarse como contrapuesto a otro sujeto, es decir, debe reconocer la subjetividad ajena, poniéndose a sí mismo $\mathrm{n}$ situación de paridad objetiva respecto a aquélla, y coordinándose, por ende, con la misma.

Cualquier criterio de determinación correlativa del obrar de varios sujetos, en forma tal que cada uno de ellos resulte obligado respecto de otro u otros, y a la obligación del uno corresponda en el otro la facultad de exigir su cumplimiento, reviste la forma de juridicidad o de la justicia genéricamente entendida, con independencia del contenido de las obligaciones y de las pretensiones que correspondan entre sujeto y sujeto.

No puede, en verdad, excluirse de la pertinencia a este género lógico una cierta determinación de tal índole de determinación intersubjetiva, porque refleje de manera inadecuada e imperfecta el carácter absoluto de la persona. En este sentido, pues, justicia es sinónimo de derecho, y así se habla por ejemplo de una justicia civil, de una justicia penal, etc.

Pero el pensamiento no puede detenerse aquí. Además de aquella primera determinación puramente formal, hay todavía otra, cuyos elementos están ya implícitos en lo que hemos dicho poco antes. Es filosóficamente legítima y psicológicamente inevitable, la cuestión acerca de si una cierta determinación jurídica corresponde o 
no a aquel principio ideal que está Ínsito categóricamente en nuestra misma naturaleza; a saber, la universalidad del espíritu que trasciende la individualidad empírica y contingente. Aquella especie de divinidad de nuestra naturaleza (est deus in nobis), por la cual nosotros, aunque ligados empíricamente al mundo de los fenómenos, nos sentimos partícipes también del otro mundo (en cuanto que poseemos, por lo menos virtualmente, ideas universales que trascienden con mucho nuestra existencia y experiencia tísica), atribuye a todo sujeto un valor absoluto, y este valor exige un reconocimiento y vale como criterio incluso allí donde resulte violado de hecho. De aquí la posibilidad, y también la necesidad, de una confrontación entre tal criterio absoluto y las normas jurídicas que aparecen positivamente formuladas en la experiencia.

La justicia se afirma entonces no como sinónimo de derecho positivo, sino como su paradigma y modelo ideal, siempre válido en su esfera, aunque sea parcial o defectuosamente realizado; así como el ideal de la virtud y el imperativo del deber ("no hacer a otro aquello que no quisieras que te fuese hecho a ti mismo",etc.) valen siempre, aun cuando innumerables veces resulten materialmente violados.

Totalmente secundaria es también aquí la cuestión de las preferencias terminológicas. Puesto que el carácter fundamental de la juridicidad es común a las determinaciones jurídicas positivas de igual forma que a las puramente ideales, nos parece que no hay razón para refutar, sino que más bien debe ser conservada, aquella distinción clásica entre Derecho natural y Derecho positivo: o bien (lo que significa lo mismo) entre justicia ideal y justicia positiva. Y la cuestión no cambia, si, como a muchos agrada, substituimos la fórmula Derecho natural por la de Derecho racional; puesto que la razón constituye precisamente la esencia de nuestra propia naturaleza, y es en todo caso el principium cognoscendi del derecho que de la misma emana ("Jus naturae cognoscitur ex ratiocinatione animi tranquili ", escribía ya CRISTIAN TOMASIO, y todavía antes, su maestro LEIBNIZ había observado: "Jus naturale est quod ex sola ratione naturali sciri potest").

Lo que importa (cualesquiera que sean las fórmulas preferidas) es no desconocer la jerarquía de los valores y los diversos órdenes de la realidad, también por lo que toca al derecho, evitando dos especies de dogmatismos, igualmente erróneos y perjudiciales. El primero de tales dogmatismos consiste en considerar la realidad empírica como la única clase de realidad, y por consiguiente el Derecho positivo con el único derecho, en tanto que el simple análisis lógico nos demuestra de una manera palmaria que la forma de la juridicidad se aplica a toda clase de relaciones intersubjetivas, siempre que, en virtud de la determinación misma, a una obligación corresponda una pretensión. Es esto suficiente, a nuestro parecer, para superar el positivismo jurídico. Pero el análisis filosófico va aún más allá, y nos muestra también que sobre la innumerables determinaciones jurídicas, positivas o no positivas, reales o lógicamente posibles, existe una escala de valores que arranca de aquel supremo, representado por el puro ideal de la justicia.

El otro dogmatismo consiste en admitir apriori, por un anticientífico preconcepto, la justicia absoluta en todo fenómeno jurídico, el cual precisamente en cuanto fenómeno no puede sino tener carácter relativo. Esta arbitraria idealización o adoración del hecho histórico es rotundamente desmentida por el mismo análisis filosófico más arriba apuntado; y es, por consiguiente, siempre un error, si bien, en ciertos casos, un error noble. Nosotros nos inclinamos a aquella tendencia de DANTE, el cual recordando la enseñanza escolástica (Lex injusta non est lex), afirmaba: Necesse est, finem enjusque juris bonum commune ese, et impossiblie est jus ese, bonum commune 
non intendens (Mon, I., cit.); puesto que esta fórmula encierra, como resulta esclarecido todavía por lo que sigue, la generosa advertencia de interpretar todas las leyes como si estuviesen encaminadas al bien común. Pero si es verdad que esta finalidad de las leyes en todo tiempo y en todo lugar hayan tenido realmente esta intención. Esta tesis dogmática sería tan inexacta como aquella otra opuesta, que quizá nadie se atrevería a sostener hoy, a saber, que en todo caso el legislador tome por fin su propia ventaja particular, o la de la propia clase social, antes que el bien de todos. Añádase, a mayor abundamiento, la consideración de que, incluso cuando la intención sea recta, no siempre resulta conforme a ella su realización; de manera que de un propósito de justicia no siempre brotan leyes justas.

Todo esto, tras tan repetidos siglos de tan varias, con frecuencias tristes y Quizá horribles experiencias, ha resultado de tal manera obvio, que no puede, en verdad, calificarse como error noble el que se comete por ciertas escuelas contemporáneas, las cuales adoran en todo caso el hecho consumado y afirman por igual la racionalidad de todas las leyes, y se inclinan siempre del lado del más poderoso, sin perjuicio, naturalmente, de traicionarlo cuando otro esté a punto de triunfar.

La concepción y el culto de la justicia no pueden suspender de las vicisitudes contingentes, ni del alternativo sucederse de las fuerzas en contraste, ni de aquel rumor mundano que, con soplo de viento, para decirlo todavía DANTE, muta nome perche muta lato, sino que deben desarrollarse y extraerse de aquella "simiente eterna" que está Ínsita, como ya enseñaba VICO, en nuestra misma conciencia.

El dogmatismo de la actualidad y de la identidad entre ser y debe ser, traducido en términos prácticos, inmoralidad y oportunismo; en términos lógicos, imposibilidad de dedicación sincera a una idea cuando no vaya acompañada de la fuerza.

Reivindicamos para la Filosofía itálica, para la Filosofía perenne, la afirmación y la defensa incluso heroica de los valores eternos del espíritu, entre los cuales destella soberano el ideal de la justicia, no como Derecho positivo, sino como Derecho natural.

Sólo a la luz de esta idea se combatió por las más santas revoluciones, como aquellas que han conducido a la liberación, a la unificación y a la grandeza de la Patria.

Al símbolo de la indeclinable justicia y concordia civil, levantado con franco desprecio de todos los peligros, en tiempos de abyección y de relajamiento de la autoridad del Estado, nosotros hemos jurado fe, y no hemos esperado para hacerlo en la hora de la victoria. Hemos así experimentado una vez más que, por encima de las leyes escritas hay otras más altas no inscritas, y que la justicia se refleja, en efecto, variamente en todas las leyes, pero sin agotarse en ninguna; por lo cual sólo ella puede en las horas grandes y decisivas imponer como deber y sacrificio supremo el hacer saltar en pedazos el orden positivo y pasar sobre él, cuando se encuentre irreparablemente corrompido, a fin de proseguir y perfeccionar con un orden nuevo aquel proceso de realización y de rei $v$ indicación de la misma justicia, que tiene por teatro la historia y por fuente inamovible e inagotable el espíritu humano. 